\title{
Constructing Worlds: Reflections on Science, Technology and Democracy (and a Plea for Bold Modesty).
}

\author{
WIEBE E. BIJKER ${ }^{2}$ \\ MAASTRICHT UNIVERSITY
}

\begin{abstract}
Can STS offer a response to "alternative facts" without falling back into naive positivism? Can STS help to make science accountable to society and make it work-make it function in our democracies and let it produce scientific knowledge? In his valedictory lecture, Wiebe Bijker looks back upon three decades of STS research in general, and upon engaging STS with questions of democratization and development in particular. He starts from the question how to study technological cultures and ends with the question how to construct them. The argument moves from the social construction of technology to constructing socio-technical worlds. Finally, when trying to understand this construction work, the analysis zooms in on the constructing worlds: on the institutions in which this construction work takes place.
\end{abstract}

\section{Keywords}

STS; SCOT; technological culture; development; democratization; RRI; biogas; India

\section{Introduction}

"We are living in a technological culture." That was the summary of my inaugural lecture in 1995 (Bijker 1995a, 2010). Today I want to move from the question how to study our technological cultures to the question how to construct them. In a few big steps, I shall take you from the social construction of technology to constructing socio-technical worlds. And finally, when trying to understand this construction work, to the constructing worlds-with the emphasis on constructing: zooming in on the worlds, the institutions, in which this construction work takes place.

\footnotetext{
- This valedictory lecture was read on May 12th, 2017 in abbreviated form at the occasion of Bijker's becoming emeritus professor at Maastricht University. For the filmed event and the abbreviated text, see: http: / / www.maastrichtsts.nl/ bijker-farewell. On that same day, an international symposium "Adventuring into STS" was held with Harry Collins, Knut Sørensen, John Law, Rosalind Williams and Shiv Visvanathan; see: http: / / www.maastrichtsts.nl/bijker-farewell .

2Email: w.bijker@maastrichtuniversity.nl

Copyright (c) 2017 (Wiebe Bijker). Licensed under the Creative Commons Attribution Non-commercial No Derivatives (by-nc-nd). Available at estsjournal.org.
} 
The starting point for science, technology \& society studies (STS), especially in the Netherlands and Scandinavia, was an engagement with societal issues in the 1970s and 1980s such as nuclear energy, the nuclear arms race, and genetic modification. From the 1980s onwards, an "academic detour" resulted in master and doctoral programs, professorial chairs, journals, book series and everything else that goes with an emerging discipline (Bijker 2013). Though I am a little biased, I'll maintain that the thrust of this academic detour into research and teaching was constructivist. Scientific facts are not dis-covered by taking away the cover of nature, peeping through the hole and picking up the facts. Rather, as the sociology of scientific knowledge (SSK), with pioneers like Harry Collins, Trevor Pinch, John Law, Donald MacKenzie, Steve Woolgar and Bruno Latour demonstrated, scientific facts are constructed in social processes in the laboratory, the seminar room, the journal's editorial office, and the lecture hall (Latour and Woolgar 1979; Collins 1985; Law 1986; Pinch 1986; MacKenzie 1979; Edge 1995). In a similar move, some of us then argued that technology is also socially constructed. Not in the trivial way that machines are designed and manufactured by people, but in the sense that the working of a machine results from social processes and not merely from applying physics, chemistry and mechanics.

\section{Biogas from Rice Straw?-Introducing SCOT}

Let me briefly illustrate this with an example. Let's talk about biogas, in India. The first time I heard about this biogas was as a potential solution to a huge problem that twice a year occurs in northern India. Farmers burn the rice straw that is left on the fields after harvesting, and a thick layer of smoke covers the foothills of the Himalayas and northern India, including India's capital, New Delhi. The smoke is not only causing traffic jams in the capital, it is also polluting the environment and it is toxic for farmers and citizens. A new chemical treatment of that rice straw now promised to make it fit for producing biogas. With that biogas, electricity could be produced and that could in turn benefit the farmers' communities-everyone happy! Well, not quite: when we analyzed the social construction of biogas, a more complex picture emerged.

We identified different relevant social groups and mapped what biogas meant for each of them. And rather than one "biogas," a whole range of different "biogases" emerged. I'll describe a few. For most farmers, the burning of rice straw is not a problem-it is a solution. Since the Green Revolution, farmers in Punjab have been charged with the responsibility "to feed the nation" and been pushed to produce up to four crops per year. After harvesting the rice, they have only three weeks to clear their fields and prepare for sowing wheat. Most of the farmers do not see another solution but burning the straw. For them biogas is not a solution, but an extra burden: collecting the straw from the fields, storing it, and transporting it to a biogas plant just costs too much labor, money and time. And additionally, Punjab villages typically have enough electricity anyway. So, this is the first biogas—a non-issue, a "no biogas."

${ }^{3}$ The project "Responsible Biogas in India" is carried out together with Govert Valkenburg, Annapurna Mamidipudi, Poonam Pandey, Rachna Arora and Ragna Zeiss. See https://www.nwo$\underline{\text { mvi.nl/project / responsible-production-biogas-india }}$ 
The second biogas we see when we explore the perspective of the small group of farmers who label themselves "organic": for these organic farmers, biogas is part of a solution, but the solution to a very different problem. Their problem is not primarily the smoke: "we know that the smoke is hazardous, but pollution is also caused by the traffic in New Delhi, so why blame us?" Their problem is that burning the straw destroys important nutrients, which instead they would like to give back to the soil. However, rice straw is problematic to plough directly back into the soil. It needs composting or mulching, and feeding it into a biogas plant would help: in addition to biogas, such a plant produces waste that can be used as organic fertilizer. So, for these farmers, biogas is not a solution to the smoke, nor a non-issue: it is a "fertilizer-producing biogas."

A third and very different relevant social group is the Ministry of Petroleum and Natural Gas (MoPNG). Their mission is to make India more energy-secure (India imports large amounts of natural gas and oil and wants to become more self-sufficient) and to meet the international $\mathrm{CO}_{2}$-emission agreements. A very ambitious biofuel program has been started which mostly builds on producing second-generation ethanol. But for a few months also biogas has been gaining importance again. Biogas is attractive since the existing distribution system for pressurized and liquid natural gas can be used for the marketing of biogas. Dr. Ramakrishna, chair of the Working Group on Biofuels, recognizes the logistical problems of collecting and transporting agricultural waste biomass, such as rice straw, but is determined to get those solved. He also realizes that rice straw needs an extra step of pre-treatment before it can be fed into a biogas plant, but he has understood that this problem is almost solved. So, through the eyes of the MoPNG we see the "biogas for energy security."

The fourth group is the Ministry of New and Renewable Energy (MNRE). This is the ministry that has been responsible for half a century of biogas practice in India. Biogas is much more prominent on their agenda than on any of the other groups' agendas. But at this moment the focus is on biogas from organic city waste. The MNRE's program of rural community-based biogas production has had a mixed success. In some states, like Gujarat, it worked really well; but in others, like Bihar and Uttar Pradesh, experiences were more negative. Mr. Dhussa, who worked a life-time with biogas, mostly as a consultant for the MNRE, has high expectations of current biogas developments. This is the right time for biogas, he argues: a huge stock of biomass waste all over India, new international $\mathrm{CO}_{2}$ emission standards, rice-straw burning that generates as much political pressure as smoke, and new chemical pre-treatment solutions. He recognizes that biogas did not get so much into the limelight as did solar and wind energy recently, but expects that this will change. From Mr. Dhussa's perspective we thus identify a fourth biogas: the "promising biogas."

The fifth-and, for the moment, last--biogas is the one that we see through the eyes of chemistry researchers. Rice straw poses an extra puzzle. Rice plants, especially the varieties grown in Punjab, contain much lignocellulose, which cannot be directly fed into a biogas or ethanol plant (Zheng, Pan, and Zhang 2009). Enzymatic processes have proved successful on laboratory scale and now need to be up-scaled. Thus, the fifth biogas is a "high-tech biogas," based on sophisticated chemical research and engineering. 
Using the biogas case, I now can briefly summarize the core concepts of SCOT, or the Social Construction of Technology (Pinch and Bijker 1984; Bijker 1995b, 2015). Instead of assuming a single self-evident line of development of a technology, SCOT describes a technology-in this case biogas-as resulting from the interactions between different social groups. The first step is to identify which social groups are relevant for biogas' development. When I then describe biogas as seen through the eyes of these relevant social groups, we see different technologies. I thus demonstrated the "interpretative flexibility" of biogas: there is not one biogas that follows its "natural" path of development, but at least five different ones. The next question, then, which I have not addressed yet, is what happens to this interpretative flexibility: which of the different biogases wins? I shall return to this question later.

\section{Science and Technology for Society}

After this brief excursion to introduce the biogas case and to review some concepts of SCOT, I now continue with the historical sketch of STS. In the late 1990s some of us began to argue that we had learned enough during our academic detour to be able to return to the societal challenges that had inspired STS in the beginning-my inaugural lecture was part of that move. This implied several lines of work for STS research. The first set of research lines is best described by starting from the science end of the relationship; the second set takes the perspective from the society end. I shall briefly review these lines of work.

Starting from the science end, the first question relates to expertise. Following the lead of the sociology of scientific knowledge, STS-ers have studied various belief systems, including science, empirically and without making any a priori assumptions about characteristics such as truthfulness or correspondence with Nature. That yielded an analysis of scientific facts as socially constructed, rather than as found in Nature. But this raised the question: if scientific knowledge is socially constructed, as religious and experiential knowledge are, does that imply that there is nothing special about scientific expertise? Can we do without science?

No, we cannot do without science. Our technological cultures are so thoroughly permeated by science and technology, that it would be silly to think so. Yes, early STS work in the 1970s demonstrated that "science is human work," to quote the title of Arie Rip's PhD thesis (Rip 1978); but that was to counter the almost priest-like status of scientists in society, which made them immune to critique and democratic governance. In the first decade of this century the popular view of science has swung completely to the other side, away from this high-status view. (I do not claim that this was caused by STS' debunking of the unwarranted a priori status of scientific knowledge, but it certainly was in sync with it.) Even the Dutch Crown Prince publicly declared the results of a scholarly report by historian Prof. Michiel Baud as "just another

"The distinction between the perspectives "from the science end" and "from the society end" is only an analytical one-in practice, both typically happen together. 
opinion." so, after two decades of demonstrating the socially constructed character of science and technology to make science and technology more subject to regular democratic governance, many STS-ers felt that it was necessary to push back in the other direction: to argue for the especially valuable character of scientific knowledge. For us, in STS, there is of course no contradiction: scientific knowledge is still socially constructed, and we spend our time on demonstrating that this social construction yields knowledge of a particular kind and special value.

As a brief intermezzo: what, then, is so special about scientific facts? In a world in which "alternative facts" figure so prominently these days, it is tempting to overstress the objectivity and certainty of scientific facts, but then we would be falling back into the pitfall of quasi objectivity - a pitfall out of which we have been climbing since the 1970s. I have no better answer than the following: scientific and scholarly facts are produced and validated by a complex institutional machinery that cultures particular values-the scientific community with its unwritten rules, scientific methodologies, peer review, etc. This does give scientific facts a special quality, but it does not imply that there cannot be scientific uncertainty, or that it is impossible that next year we will conclude that a particular statement is false, which today we still consider a true fact. It also shows that controversy between scientists is normal and that there is no reason to lose trust in science.

One example of STS work that tried to describe the making of scientific facts for use in society is the study that Roland Bal, Ruud Hendriks and I made of the Health Council of The Netherlands (Bal, Bijker, and Hendriks 2002; Bijker, Bal, and Hendriks 2009). ${ }^{\circ}$ During more than hundred years this Council of State has been advising the Dutch government "on the state of scientific knowledge" and it has done so with remarkable success and-most of the timeunquestioned authority, whichever way the winds of popular appreciation of science, authority, and elites were blowing. This seemed like a strategic research site for studying the role of scientific knowledge in society and democracy. We developed a theory of scientific advice in which we showed how the scientific truth of the Health Council's front-stage advisory reports is constructed by a variety of back-stage social processes in its committees. Science is socially constructed and it has special value in society because of that construction process. The King of the Netherlands now seems to make a similar plea for valuing scientific knowledge. In his 2016 Christmas speech, King Willem Alexander warned: "One often hears 'Reality is just a perception.' But if perception clouds the view of reality, the foundation of daily life becomes quicksand." (I would like to interpret this as a positive change in his assessment of the value of science, when compared to his previous "just an opinion" statement.)

s Television interview with Crown Prince Willem-Alexander and his fiancée Máxima Zorreguieta by Maartje van Weegen en Paul Witteman, broadcasted by NOS on 18 January 2002. The report investigated the role of his fiancée's father as under-secretary in the Argentinian Videla government. See also (Baud 2001). ${ }^{\circ}$ Other examples are (Jasanoff 1990) and (Collins and Evans 2002).

; "'Beleving is werkelijkheid', hoor je vaak. Maar het fundament van het dagelijks leven wordt drijfzand als beleving het zicht op de werkelijkheid verdringt" (W. Bijker translation).

https: / / www.koninklijkhuis.nl/ documenten/ toespraken/2016/12/25/ kersttoespraak-van-zijne-majesteitde-koning-25-december-2016 (last retrieved: 23 January 2017). 
The line of research I have just discussed focuses on the production of knowledge for democracy (in this case advisory knowledge). A second line of work asks about the use of scientific knowledge by citizens and policy makers in democracy. The distinction that Harry Collins and Robert Evans introduced between contributory and interactional expertise is very insightful; it is also a distinction that I found quite effective when explaining the feasibility of using scientific knowledge in democratic processes to people outside STS (Collins and Evans 2007). An important question when thinking about democratizing technological cultures is: is science not too difficult for citizens and politicians? Can only those policy makers who have been trained as scientists read the expert advisory knowledge produced by the Health Council, or can citizens and politicians without scientific training also benefit? Of course, such citizens and politicians do need some knowledge, some relevant expertise; but they only need "interactional" expertise-expertise to interact with scientists. They do not need "contributory" expertise-the expertise to contribute new scientific knowledge.

An example that this indeed does work can be found in the Netherlands National Dialogue on Nanotechnology.s The Dutch government decided "to stimulate and facilitate a societal dialogue on the social and ethical aspects of nanotechnology." It thus made a clear choice in the so-called Collingridge dilemma-either you assess a technology in its early stage when you can still change its course but you have no insight into its (positive and negative) consequences, or you wait to evaluate the technology until you better understand its consequences, but then it is too late to change its course (Collingridge 1980). The government decided to have this public dialogue in a very early stage of the development of nanoscience and technology. With this decision, the government followed the advice of the Health Council of the Netherlands, which had argued that in nanotechnologies a combination of uncertain and ambiguous risks occurs and that therefore a broad range of stakeholders and citizens needs to be involved in the decisionmaking process about the future of nanoscience in society (Gezondheidsraad 2006). The results of this two-year dialogue process, involving thousands of citizens and stakeholders, was the following: a small but significant increase in understanding of nanotechnologies, a small but significant increase in recognizing that risks were involved, and finally an increase in support for continued nano research. This yields at least two conclusions. First, that citizens are not afraid of new science and technology, but that they are afraid of governments, scientists and industrialists who do not tell them everything, including the relevant risks and uncertainties. Second, that it is possible to discuss such complex scientific issues with citizens and stakeholders who are not trained in that specific science-who have only interactional and no contributory expertise.

Holding this societal dialogue involved a lot of work; more to the point, it involved designing, organizing, maintaining-or, in one word, constructing. A series of conscious design choices was made in constructing the dialogue (Bijker 2014). One example of such a choice was that we were not to spend the $4 \mathrm{M} €$ ourselves, but rather outsource most of the activities. Two open calls were published in which we invited individuals and organizations to propose projects that would address some aspect of the societal dialogue. These projects could have budgets

: See (http: / / www.nanopodium.nl/CieMDN/ (last retrieved on 01-02-2017). 
between $15 \mathrm{k} €$ and $130 \mathrm{k} €$. The Committee centrally organized the kick-off and closing events (both with the responsible Cabinet Minister participating), and some conferences, workshops, a festival, and the Nanopodium web portal. The outsourced projects did the bulk of the work and produced books, a special journal issue, exhibitions, TV programs, design \& art objects, a children's novel, websites, games, course material for schools, Internet films, comics, theatre performances, and a variety of group and panel discussions. This all resulted in a national dialogue that included a broad range of stakeholders and citizens, used a wide variety of activities and formats, and reached out in a colorful spectrum of media.

I shall now turn to the perspective that starts from the society end of the science-society relationship, when society is taking the lead. This includes the social construction of scientific knowledge and technical artifacts as well as the political and social shaping of science and innovation agenda's, policies and research management. The first line of work, comprising, for example, the Sociology of Scientific Knowledge (SSK), Actor-Network Theory (ANT) and the Social Construction of Technology (SCOT), I have mentioned already. I now want to focus on the other line-shaping research agendas, science policy, and research management.

\section{Societal Challenges Taken Up by Science and Technology}

Viewed from a general and long-term perspective, societies have always influenced their science and technology. From the Long Island bridges in race-segregating New York, to the stirrup in feudal Europe, from the scientific method in puritan England, to gunpowder in Chinatechnologies and scientific knowledge are shaped by the societies in which they are being developed (Winner 1980; Joerges 1999; White Jr. 1962; Whitney 2013; Merton 1938 (1970); Needham and Wang 1954). This is, however, a quite general and unspecific claim. I want to be more specific and will zoom in on science policy in the present, drawing on my experiences in the Dutch National Research Agenda (NWA) and in the Netherlands Organization for Scientific Research (NWO), the Dutch research funding council.

Until some two decades ago, a social contract between science and society existed as formulated in 1945 by Vannevar Bush in his report to the President of the United States, Science, The Endless Frontier (Bush 1945) if society funds fundamental science without meddling with the science agenda, science will give back to society useful knowledge and innovations. This social contract is changing. The European Framework Programmes for scientific research have been following a policy-driven innovation agenda for two decades, and the present Horizon2020 program explicitly takes "Grand Societal Challenges" as its starting point. The reasoning now is: our societies are confronted by these grand challenges-health, food, sustainability, climate change, security-and we want science and engineering to help us address these. In the same spirit, The Netherlands had its Dutch National Research Agenda (NWA). Though some of my STS colleagues have been quite critical of this endeavor, if only because of its high investments in

, For more details see the project's website: http:/ / www.wetenschapsagenda.nl / ?lang=en. 
time and money, I prefer to consider the NWA more positively as another interesting experiment with democracy.

In this NWA experiment, everyone in the Netherlands was invited to submit questions to science-questions to be researched. Citizens, stakeholders, scientists, NGOs, ministries, municipalities, universities, businesses-together they generated more than 11,000 questions. These were then filtered and validated by the Royal Netherlands Academy of Arts and Sciences (KNAW). Some questions were filtered out-for example because they could already be answered by existing knowledge. Others were considered impossible to research scientifically. My favorite example of such a question is: "Does life after death exist, and can we commercialize it?"10 This filtering of questions was done anonymously: the KNAW committees could not see whether a question was asked by a Nobel laureate or by a school kid. Some questions were thus discarded. To make the rest of the process manageable, the remaining questions were grouped in some 250 overarching clusters. These 250 clusters were then discussed in three conferences: "Science4Science," "Science4Competitiveness" and "Science4Society." The outcomes of the conferences were then processed by the NWA Steering Group into 25 routes. A route does two things: it offers a path for science through a subset of the 250 question clusters, and it suggests a path for society towards addressing an important societal challenge. In December 2015, these routes, clusters and underlying questions were presented in an interactive on-line National Research Agenda. In 2016, the routes were elaborated and used as building blocks for a Science Investment Agenda for the Dutch government, arguing for an extra 1 billion €uros per year for research. We do not know yet what the new government will do with this investment recommendation, nor how the National Research Agenda will concretely translate into funding research. What we do know is that new groups of citizens and organizations actively engaged in thinking about science and technology and their potential for society. And because scientists engaged too, and indeed listened well, this is an example of society shaping science.

The second example is NWO, as illustrated by two recent changes in its practice and structure. The first change was the inclusion of the top-sector policy of the Ministry of Economics in the NWO research funding practices, and the second was the transition of NWO to a new organizational form, by January 2017. In 2010, the Dutch Government had decided that NWO should spend 100 M€uros to top-sector research. These top sectors had been selected by the Ministry of Economics to stimulate research and innovation in sectors that were most prominent and promising in the Dutch economy." The management of this research and innovation was to be shared between science and industry in so-called Knowledge and Innovation Consortia (Top consortia voor Kennis en Innovatie, TKIs) and research projects had to be carried out by publicprivate partnerships. This implied an enormous investment by NWO staff and leadership: funding conditions, calls for proposals, selection criteria, and definitions of quality and relevance-these all had to be constructed. Whatever one may think of the top-sector policy in general, I do think that NWO succeeded in developing a set of practices to manage research

${ }^{10}$ This question was not submitted by a Dutch citizen, but invented by Henk Molenaar, Head of the NWA staff, as an example of a question that would be filtered out.

"See https:/ / www.topsectoren.nl (last accessed on 22-04-2017). 
funding under this scheme, which allowed societal shaping of research without jeopardizing the scientific quality of it." Responsible Research and Innovation (RRI, in Dutch "Maatschappelijk Verantwoord Innoveren") is one such program to which I shall return below.

The second way in which NWO adapted itself to allow more influence of society on science was NWO's recent transition into a different organizational form. From an organization with nine different disciplinary research councils and a range of interdisciplinary taskforces, the new NWO comprises of only four disciplinary domains and two cross-disciplinary Steering Groups." One of the explicit aims of this reorganization was to be more transparent to the outside world and offer societal actors more easy access to NWO to discuss possible research agendas. Let me use the Steering Group WOTRO/Science for Global Development as an example. The research funded by this steering group aims at contributing to the UN Sustainable Development Goals and to inclusive global development. This research typically cuts across all disciplinary domains. A broad range of societal partners-from the Ministry of Foreign Affairs (including Development Cooperation) and the Dutch universities, to NGOs like ICCO, HIVOS and CORDAID—can approach WOTRO with research questions and funding possibilities. WOTRO will then coordinate with the relevant sections within the various NWO domains to organize the funding, formulate a call for proposals, manage the application selection process, monitor the research, and help with the knowledge utilization afterwards.

In the recent Handbook of STS we have argued for the need for and benefit of drawing STS and development more closely together (Khandekar et al. 2017). We reviewed how, since development was conceived in this sense after World war II, science and technology have played a central role in development-developing countries are technological cultures too.

Postcolonial studies and STS research have highlighted the unequal relations between the West and the East that characterize the development of science and technology. This scholarship then proceeds to question and rethink received dichotomies such as global/local, firstworld/third-world, Western/indigenous, modern/traditional, developed/underdeveloped, bigscience/small-science, which effectively work to maintain Western dominance. Scholars interested in the knowledge politics of development highlight the irresolvable paradox that is at the heart of colonial discourse: it simultaneously posits Western science and colonial tradition as fundamentally opposed, while also depending on the ability of colonized populations to be reasonable enough to acknowledge themselves as less knowledgeable (Prakash 1999). This makes clear that development cannot be a straightforward application of science and technology to solve a problem-which is indeed a quite general insight from STS. In the context of development, this too-narrow focus on "technological fix" explains "how various interventions have often failed and even exacerbated the very conditions that they were meant to address" (Khandekar et al. 2017: 675). Well-intentioned developmental interventions often fail because they do not recognize the complex and interconnected nature of technological cultures. Looking at the effects of large-scale technocratic interventions such as large dams or the Green Revolution,

${ }_{12}$ See https: / / www.nwo.nl/beleid/topsectoren (last accessed on 22-04-2017).

${ }^{13}$ https:// www.nwo.nl/binaries/content/gallery/nwo/algemeen/over-nwo/organogram_2017_nl.jpg (last accessed on 22-04-2017). 
it is not surprising that some critical scholars see Western modernity, including its science and technology, as inherently violent (Nandy 1990; Visvanathan 1997).

One way to rethink development agendas, and the role of science and technology therein, is to put vulnerability of technological cultures center stage. This allows a broadening of the issues beyond hazard and risk. STS researchers have expanded existing vocabularies of risk by adding cultural to societal, Gemeinschaft to Gesellschaft, solidarity to security, precaution to prevention, and justice to legality (Hommels, Mesman, and Bijker 2014). We have argued that a more open-ended qualitative and discourse-based attention to ethics and justice needs to complement current styles of governance, policy making, and intervention. This is in line with previous work in STS that broadened the unit of analysis from the scientific fact and the technical artifact to actor-networks and socio-technical ensembles. This broadening has direct implication for our thinking about development and intervention. A broader spectrum of intervention points becomes visible and a broader spectrum of intervention strategies becomes available.

\section{STS: Understanding and Intervening}

Let me return to our current biogas project in India. I have introduced SCOT as a research heuristic: by identifying the relevant social groups, I could describe the interpretative flexibility of biogas. SCOT thus helps to make the research question more precise: how does the interpretative flexibility of biogas diminish, resulting into one dominant biogas-in other words, how can we trace the social construction of biogas? Using SCOT for research, however, also means making an intervention. Such intervention is inevitable, like in many forms of social science research: research subjects are likely to reflect upon their identities and practices after participating in the research or after reading the research findings. But intervention can also be deliberate and planned, as is often the case in development research. Identifying new social groups and arguing their relevance may change the discourse. The symmetry principle of being impartial to the eventual success or failure of a technology while studying it may even affect the power balance between social groups." Our symmetrical analysis of biogas, for example, called for an effort to formulate and explicate the organic farmers' views on biogas: without that extra work by the researchers, the analysis would have been less scholarly robust. But it also meant empowering the farmers and thus an intervention into the sociotechnical ensemble of rice straw and biogas, beyond research.

So, could it be that we are not only studying the social construction of biogas, but that our interventions also actively contribute to that social construction? What mandate would we have, as researchers, to do so? Where to draw the line between understanding and intervening, between research and development? Or is it not possible to draw such a line and should we rethink research—its practices, methodologies, epistemologies? I do think it pertinent for much of

${ }^{14}$ For the introduction of the symmetry principle in science studies, see (Bloor 1973, 1976). For application in wider STS, see (Bijker 1995b); and for elaboration for the development domain, see (Mamidipudi 2016). 
STS and certainly for all development-related research to ask such questions." Programs of "Responsible Research and Innovation" (RRI) underline the pertinence and timeliness for such a rethinking exercise.

RRI programs explicitly seek to connect societal challenges with research goals and questions. In the Netherlands, the RRI program is part of the top sector funding by NWO." Our biogas project is funded under this scheme. RRI is only the latest approach in five decades of STS to improve technology and its successful embedding in society, like technology assessment, constructive technology assessment, participatory technology assessment, ELSI-research, public engagement with science, etc. One way to characterize RRI is by its normative goal. It aims at a more responsible development and use of science and technology in society and at technology and research that have "the right impacts" (Schomberg 2011). The second way to characterize RRI-and a way to answer what is "right" in the previous question-is by the process that RRI advocates: it requires anticipation of future societies that we wish, reflexivity of researchers and innovators on the effects of their work, inclusion of relevant stakeholders, and responsiveness to the needs and ambitions of society (Stilgoe, Owen, and Macnaghten 2013).

Being alerted by RRI's raising of normative, future-oriented issues, we can identify even more biogases than the ones I reviewed previously. The number-six biogas is the one we see when using the European ideals of better recycling waste and of climate change policies. This comes closest to the biogas with which I started today, the biogas as solution to huge global societal challenges-the "everyone-happy biogas." The number-seven biogas is the "corporate biogas," the biogas that offers a strategy for large industrial corporations to combine their corporate social responsibility with making money, by developing a biogas that is not only environmentally sustainable but also financially sustainable. And I could even identify a "holy biogas" as number eight. This is a by-product from the cow, since cow dung has the best bacteria to break-up rice straw. This goes back to ideas of local sustainability and recycling where nothing is "waste," at a time when cows were part of every household, treated as almost part of the family, and loved and prayed to. This is proper farmers' knowledge, but it is now being hijacked by Hindu-religious groups who thus see biogas as a way of reviving the glorious past of a Hindu India, while having the benefits of enough fuel in their present socio-technological world.

So, here we are: studying the social construction of biogas as an alternative to rice-straw burning and at the same time intervening in Indian society by asking RRI-type questions and by empowering weak social groups to participate in the broader social innovation process. But to do this, as researchers we must own up to this interventionist identity and recognize that we are ourselves a relevant social group. And like every relevant social group we bring a specific perspective shaped by our background and history. Not recognizing this would place us outside

${ }^{15}$ See also (Downey and Zuiderent-Jerak 2017) and the new journal ESTS, http:/ / estsjournal.org/index (last accessed on 22-04-2017)

${ }^{16}$ The RRI program (in Dutch: Maatschappelijk Verantwoord Innoveren, MVI) is carried out by the NWO domains SSH (Social Sciences and Humanities), Science, and WOTRO. See http:/ / www.nwo.nl/en/research-and-results/programmes/responsible+innovation (last accessed on 2204-2017). 
the analysis and give us a kind of immunity and god-like status. This would be politically unfair and scholarly unwarranted: how could we claim to be more special than any of the other groups-if it is about intervening in Indian society? It would even be opposite to the core idea of RRI, in which the views on future society and the values to be cherished are to be solicited from stakeholder groups. But now we do have a problem-since we are special, but only as researchers and not as interventionists. Scientific facts have a special and precious status as compared to other facts, and, as I said before, I do want to contribute to maintaining that status and, where needed, restoring the status and the trust in science.

Talking of trust, what does the previous analysis of the role of researchers as also interventionists imply for our democracies? I do not join the chorus of lamenting that there is not enough trust in science. Research by the Rathenau Institute and the Netherlands Scientific Council for Government Policy (WRR) has shown that Dutch citizens still trust scientists—at least much more so than that they trust politicians and journalists (Tiemeijer and Jonge 2013; Blankesteijn, Munnichs, and Drooge 2014). Also, the scientific advice by councils like The Health Council of the Netherlands and the WRR is generally highly respected and trusted. And the societal dialogue on nano resulted in increased trust of the Dutch population in nano scientists, recognizing that scientists could be open about the uncertainties in scientific knowledge and the risks in technologies. I do want to stress, however, the symmetrical character of trust. Yes, society should trust science; but science should trust society, too. And that is exactly what RRI asks us to do: to take social groups in society seriously when investigating innovation, to listen to stakeholders' views of risks and benefits of innovation and knowledge.

Symmetrical trust may be a laudable aim, but to achieve this we cannot escape thinking about power relations. Extending the social construction of technology, I developed a concept of power that combines a micropolitics of power with a semiotic power structure." This concept helped me to explicate how power could be used for summarizing a SCOT analysis of technology and society, while not giving power the role of explanatory variable. Let me now try to extend this use of "power" from the analysis of technology development to the questions we just raised: how might power differences obstruct the symmetrical trust relationships that our technological cultures need for democratic governance?

To do this, I draw on recent work with Else Bijker and Robert Sauerwein, when we tried to understand the working of Controlled Human Malaria Infection trials (CHMIs) (Bijker, Sauerwein, and Bijker 2016). We showed how "tandems of trust and control" make the social construction of scientific knowledge happen. Tandems of trust and control are specific combinations of trust and control, in which these two work together, coproduce each other, or partly substitute for each other. Often, trust and control are considered in contrasting ways. Trust tends to involve personal relationships, generally asks for some symmetry, and is commonly associated with subjectivity; control involves rules and protocols, often is hierarchical, and is associated with objectivity and standardization. We have argued, however, that trust and control

${ }^{17}$ The micropolitics of power uses an interactionist, enabling and construction-oriented perspective; and the semiotic power uses a structural, constraining and technical-determinist perspective (Bijker 1995b: 260-266). 
are not just alternatives that substitute for each other when one does not suffice, but that they actually work in conjunction. Trust benefits from knowing that there is some measure of control. Volunteers in the malaria trials, for example, trust the researchers because they know that the ethical research committee controls the trial design. Control, similarly, cannot exist without trust. An ethical research committee can exert control by checking and then approving a research protocol, but still must trust that the researcher will stick to her protocol. Hence, our use of the term "tandem": trust and control coproduce each other, but within that tandem they can also partly replace each other or even work against each other. Trust and control are bound together as the two riders on a tandem bicycle. When both riders peddle, their combined power moves the bike forward swiftly, but it is also possible for one to freewheel or even pedal backwards, so that the other needs to push harder.

Now back to the power relations between social groups in our technological cultures. It is one thing to argue, as I have done, that a broad range of expertise is relevant. But that does not mean that there are no hierarchical differences; some groups have more power to push their expertise than others. Some groups can push their definition of the problem more than others. Our concept of a tandem of trust and control suggests that by building up new forms of control, new trust can be created too.

Let me return to biogas, for the last time. How will that story end? Which worlds will be constructed, which of these will win? Will it be the "holy biogas" surfing on Narendra Modi's violent Hindu-populist nationalism; or the "corporate biogas" sailing under corporate responsibility flag; or the "fertilizer-producing biogas" by the organic farmers; or will we stay with the current "no biogas"? Asking which of these worlds will win the construction struggle is asking about how the different groups with their different knowledge systems, different values, different visions, different interests relate. But is this the kind of democracy that we want: a struggle to determine who is strongest in constructing his world? If I draw on our vulnerability work, a different set of criteria for rethinking our democracies lights up. These are about community, justice, precaution, solidarity, plurality, variability, and creativity. They are about global inclusivity, sustainable development, and guarding fundamental human and ecological rights.

Is this romantic daydreaming, ignoring power relations? Not necessarily. One way of summarizing three decades of STS work is that the creation of knowledge and technology is not a matter of individual genius or a battle between good and bad people; instead, knowledge is produced and interacts with society through complex social processes and institutional machineries. It is these institutional machineries that make the quality of democracy, that translate values into governance: the back-stage processes in Dutch advisory councils as well as Indian NGO practices to organize creative dissent (Quartz 2011), and the Dutch societal dialogues on emerging technologies as well as an RRI process to shape Indian biogas. The way these machineries and practices are organized is not innocent: they will help to realize certain values or frustrate others, depending on how exactly they are shaped.

So, this was the challenge for our final biogas conference in September 2017: how can we devise mechanisms of deliberation, fact checking, learning, consensus building, accepting 
differences, so that groups can see that things could indeed be otherwise than in their own limited perspective? How, in sum, can we engage them in constructing a world that solves the problems of rice-straw burning, farmers' livelihoods, ecological sustainability, India's energy provision, and industries' economic stability? Here, research and intervention will come together: we will present our findings, though not as a technocratic dictate that can prescribe one solution; we will also intervene by creating platforms to make the social groups interact with each other in novel ways and thus generate new solutions that no one may yet have seen.

This challenge exemplifies the fundamental question that I have been talking about today, without once mentioning it clearly. How can we make science accountable to society and make it work-make it function in our democracies and let it produce scientific knowledge? How can researchers give all relevant social groups their due and play their own role as scholars? How can a Dutchman recognize the differences in power-between West and East, between white and brown, between male and female, between academic and not formally trained-and take his responsibility to act in the world and contribute to constructing a better one?

\section{Conclusion}

My friend and colleague Trevor Pinch always says: try to make only one point in a presentation, and you'll probably end up making two. So, my answer to these questions, as the take-home message for today, is twofold: one about societal institutions and the second about personal style.

First message: to construct a world for the next generations that can cope with the grand challenges that we face and do this in democracy and without war, we need to invest in our societal institutions, in the constructing worlds, in the machineries of democratic deliberation and knowledge production-advisory councils, peer review, high-quality journalism, public dialogues, open source science, a strong civil society, scholarly ethics review, etc. Second message: whether we are researchers, activists or citizens, we all need to strike a balance between confidence in our own expertise and modesty when listening to others who speak from another expertise-we need to cherish a style of "bold modesty."

\section{Dedication}

This lecture was about constructing worlds, about using STS to make a better world for next generations. I cannot dedicate this lecture to all the children of this world-that would be too pretentious. Instead, I dedicate this lecture to our two grandsons, Waldemar and Tristan.

\section{Author Biography}

Wiebe E. Bijker is emeritus professor at Maastricht University and professor of Technological Culture at the Norwegian University of Science and Technology in Trondheim (NTNU). He is currently Chair of the Steering Group NWO-WOTRO/Science for Global Development and board member of the Rathenau Institute. Bijker received the 2006 John Desmond Bernal Prize 
from the Society for Social Studies of Science and the Thomson Scientific, and the 2012 Leonardo da Vinci Medal from the Society for the History of Technology. For more details, see: https:// www.maastrichtuniversity.nl/w.bijker.

\section{References}

Bal, Roland, Wiebe E. Bijker, and Ruud Hendriks. 2002. Paradox van wetenschappelijk gezag. Over de maatschappelijke invloed van adviezen van de Gezondheidsraad, 1985-2001. Den Haag: Gezondheidsraad.

Baud, Michiel. 2001. Militair geweld, burgerlijke verantwoordelijkheid: Argentijnse en Nederlandse perspectieven op het militaire bewind in Argentinië (1976-1983). 's-Gravenhage: Sdu Uitgevers.

Bijker, Else M, Robert W Sauerwein, and Wiebe E Bijker. 2016. "Controlled human malaria infection trials: How tandems of trust and control construct scientific knowledge." Social Studies of Science 46 (1):56-86. doi: 10.1177/0306312715619784.

Bijker, Wiebe E. 1995a. Democratisering van de Technologische Cultuur, Faculteit der Cultuurwetenschappen. Maastricht: Rijksuniversiteit Limburg. inaugurale rede.

Bijker, Wiebe E. 1995b. Of bicycles, bakelites, and bulbs : toward a theory of sociotechnical change, Inside technology. Cambridge, Mass.: MIT Press.

Bijker, Wiebe E. 2010. "Democratization of Technological Culture." In Science and Technology Studies at Maastricht University. An Anthology of Inaugural Lectures, edited by Karin Bijsterveld, 13-41. Maastricht: Maastricht University Press.

Bijker, Wiebe E. 2014. "Technology Assessment-The State of/at Play. Towards a hybrid and pluriform process of governance of science and technology." In Technology Assessment and Policy Area of Great Transitions, edited by Tomas Michalek, Lenka Hebakova, Leonhard Hennen, Constanze Scherz, Linda Nierling and Julia Hahn, 23-36. Prague: Technology Centre ASCR.

Bijker, Wiebe E. 2015. "Social Construction of Technology." In International Encyclopedia of the Social \& Behavioral Sciences, 2nd edition, edited by James D. Wright, 135-140. Oxford, Amsterdam, etc.: Elsevier Science Ltd.

Bijker, Wiebe E. . 2013. "Good Fortune, Mirrors, and Kisses. Da Vinci Medal Address." Technology E Culture 54 (3):600-618.

Bijker, Wiebe E., Roland Bal, and Ruud Hendriks. 2009. The paradox of scientific authority : the role of scientific advice in democracies, Inside technology. Cambridge, Mass.: MIT Press.

Blankesteijn, M., G. Munnichs, and L. van Drooge. 2014. Wetenschap als strijdtoneel-Publieke controversen rond wetenschap en beleid. Den Haag: Rathenau Instituut.

Bloor, David. 1973. "Wittgenstein and Mannheim on the sociology of mathematics." Studies in History and Philosophy of Science Part A 4 (2):173-191. doi: http:/ / dx.doi.org/10.1016/0039-3681(73)90003-4.

Bloor, David. 1976. Knowledge and Social Imagery. London: Routledge and Kegan Paul. 
Bush, Vannevar. 1945. Science, the endless frontier. A report to the President. Washington: U.S. Office of scientific research and development.

Collingridge, David. 1980. The social control of technology. New York: St. Martin's Press.

Collins, H. M. 1985. Changing order : replication and induction in scientific practice. London; Beverly Hills: Sage Publications.

Collins, H.M., and R. Evans. 2007. Rethinking Expertise. Chicago, IL: The University of Chicago Press.

Collins, H.M., and Robert Evans. 2002. "The Third Wave of Science Studies: Studies of Expertise and Experience." Social Studies of Science 32 (2):235-296.

Downey, Gary Lee, and Teun Zuiderent-Jerak. 2017. "Making and Doing: Engagement and Reflexive Learning in STS." In The Handbook of Science and Technology Studies, 4th edition, edited by Ulrike Felt, Rayvon Fouché, Clark A. Miller and Laurel Smith-Doerr, 223-251. Cambridge, MA: MIT Press.

Edge, David. 1995. "Reinventing the Wheel." In Handbook of science and technology studies, edited by Sheila Jasanoff, Gerald E. Markle, James C. Petersen and Trevor Pinch, 3-23. Thousand Oaks, Calif.: Sage Publications.

Gezondheidsraad. 2006. Health significance of nanotechnologies. Den Haag: Health Council of the Netherlands.

Hommels, Anique, Jessica Mesman, and Wiebe E. Bijker, eds. 2014. Vulnerability in Technological Cultures. New directions in research and governance, Inside Technology. Cambridge, MA: MIT Press.

Jasanoff, Sheila. 1990. The Fifth Branch. Science Advisers as Policymakers. Cambridge, MA: Harvard University Press.

Joerges, Bernward. 1999. "Do Politics Have Artefacts?" Social Studies of Science 29 (3):411-431.

Khandekar, Aalok, Koen Beumer, Annapurna Mamidipudi, Pankaj Sekhsaria, and Wiebe E. Bijker. 2017. "STS for Development." In The Handbook of Science and Technology Studies, 4th edition, edited by Ulrike Felt, Rayvon Fouché, Clark A. Miller and Laurel Smith-Doerr, 665-693. Cambridge, MA: MIT Press.

Latour, Bruno, and Steve Woolgar. 1979. Laboratory life : the social construction of scientific facts, Sage library of social research $v 80$. Beverly Hills: Sage Publications.

Law, John. 1986. "On power and its tactics: a view from the sociology of science." Sociological Review 34:1-38.

MacKenzie, D. 1979. "Karl Pearson and the professional middle class." Annals of Science 36 (2):125-143. doi: 10.1080/00033797900200441.

Mamidipudi, Annapurna. 2016. "Towards a theory of innovation for handloom weaving in India." PhD PhD, MUSTS, Maastricht University.

Merton, Robert King. 1938 (1970). Science, technology \& society in seventeenth century England. 1st American ed. New York,: H. Fertig.

Nandy, Ashis, ed. 1990. Science, Hegemony and Violence: A Requiem for Modernity. New Delhi: Oxford University Press. 
Needham, Joseph, and Ling Wang. 1954. Science and civilisation in China. <v. 1-4; vols. Cambridge Eng.: University Press.

Pinch, Trevor. 1986. Confronting Nature. Dordrecht: Reidel.

Pinch, Trevor J., and Wiebe E. Bijker. 1984. "The Social Construction of Facts and Artifacts: or How the Sociology of Science and the Sociology of Technology might Benefit Each Other." Social Studies of Science 14 (3):399-441.

Prakash, Gyan. 1999. Another Reason: Science and the Imagination of Modern India. Princeton, NJ: Princeton University Press.

Quartz, Julia. 2011. Constructing Agrarian Alternatives. How a creative dissent project engages with the vulnerable livelihood conditions of marginal farmers in South India. Maastricht: Universitaire Pers Maastricht.

Rip, Arie. 1978. Wetenschap als mensenwerk. Over de rol van de natuurwetenschap in de samenleving. Baarn: Ambo.

Schomberg, René von. 2011. "Prospects for Technology Assessment in a framework of responsible research and innovation." In Technikfolgen abschätzen lehren: Bildungspotenziale transdisziplinärer Methoden, edited by M. Dusseldorp and R Beecroft, 39-61. Wiesbaden: VS Verlag für Sozialwissenschaften.

Stilgoe, Jack, Richard Owen, and Phil Macnaghten. 2013. "Developing a framework for responsible innovation." Research Policy 42:1568-1580.

Tiemeijer, Will, and Jos de Jonge. 2013. Hoeveel vertrouwen hebben Nederlanders in wetenschap? Den Haag: Rathenau Instituut.

Visvanathan, Shiv. 1997. A carnival for science : essays on science, technology, and development. Delhi ; New York: Oxford University Press.

White Jr., L. 1962. Medieval Technology and Social Change. Oxford: Oxford University Press.

Whitney, Elspeth. 2013. "The Lynn White Thesis. Reception and Legacy." Environmental Ethics 35 (3):313-331. doi: 10.5840 / enviroethics201335328.

Winner, Langdon. 1980. "Do Artifacts Have Politics?" Daedelus 109 (1):121-136.

Zheng, Yi, Zhongli Pan, and Ruihong Zhang. 2009. "Overview of biomass pretreatment for cellulosic ethanol production." Int. Journal of Agricultural \& Biololical Engineering 2 (3):5168. 